\title{
Nanocomposite based on graphene and intercalated covalent organic frameworks with hydrosulphonyl groups for electrochemical determination of heavy metal ions
}

\author{
Fei Pan ${ }^{1,2,3} \cdot$ Chunyi Tong ${ }^{4} \cdot$ Zhaoyang Wang $^{3} \cdot$ Haitao Han ${ }^{1} \cdot$ Pei Liu ${ }^{5} \cdot$ Dawei Pan ${ }^{1} \cdot$ Rilong Zhu $^{3}$
}

Received: 30 May 2021 / Accepted: 24 July 2021

(C) The Author(s), under exclusive licence to Springer-Verlag GmbH Austria, part of Springer Nature 2021

\begin{abstract}
An electrochemical sensor constructed by intercalated composites was developed for determination of heavy metal ions. The intercalated composites were composed of hydrosulphonyl functional covalent organic frameworks (COF-SH) and graphene (G). The presence of numerous adsorption sites, such as 18 sulfur atoms and 30 nitrogen atoms per big circle of COFs on COF-SH, was beneficial for the accumulation of heavy metals, while the graphene enhanced the electrical conductivity. The obtained sensor under the optimal conditions successfully detected the presence of heavy metal ions in coastal water samples at concentrations ranging from 1 to $1000 \mu \mathrm{g} \mathrm{L}{ }^{-1}$. The detection limits of $\mathrm{Cd}$ (II), $\mathrm{Pb}$ (II), $\mathrm{Cu}$ (II), and $\mathrm{Hg}$ (II) were 0.3, 0.2, 0.2, and $1.1 \mu \mathrm{g} \mathrm{L}^{-1}$, respectively. Furthermore, the sensor still exhibited good stability after multiple uses less than $5 \%$. When it is used in the analysis of actual samples, the recovery of standard addition is higher than $95 \%$. In sum, the combination of hydrosulphonyl functional COFs with graphene looks very promising for the assembly of sensors with high sensitivity toward the determination of heavy metal ions for coastal environmental monitoring.
\end{abstract}

Keywords Nanocomposite $\cdot$ Covalent organic frameworks $\cdot$ Graphene $\cdot$ Heavy metal $\cdot$ Sea water analysis $\cdot$ Electrochemical sensors

\section{Introduction}

Nowadays, heavy metal ion (HMI) pollution has gradually become a serious environmental problem due to its greater potential harm. In particular, heavy metal pollution of coastal waters has attracted increasing concerns due to the unregulated discharge of industrial polluted waters containing excess

Fei Pan and Chunyi Tong are the first author.

Dawei Pan dwpan@yic.ac.cn

Rilong Zhu zrlden@hnu.edu.cn

1 CAS Key Laboratory of Coastal Environmental Processes and Ecological Remediation, Shandong Key Laboratory of Coastal Environmental Processes, Research Center for Coastal Environment Engineering Technology of Shandong Province, Yantai Institute of Coastal Zone Research, Chinese Academy of Sciences, Chunhui Rd 17, Laishan District, Yantai, Shandong Province 264003, People's Republic of China amounts of heavy metal ions [1], which have serious impacts on quality of coastal waters and related biosystems [2]. Hence, the development of sensitive and selective methods for the detection of trace HMIs is of great importance for environmental remediation and public health.

Common methods used for the determination of heavy metal ions include inductively coupled plasma atomic
2 University of Chinese Academy of Sciences, Beijing 100049, People's Republic of China

3 College of Chemistry and Chemical Engineering, Advanced Catalytic Engineering Research Center of the Ministry of Education, Hunan University, Lushan Rd (S), Yuelu District, Changsha, Hunan Province 410082, People's Republic of China

4 College of Biology, Hunan University, Changsha 410082, People's Republic of China

5 State Environmental Protection Key Laboratory of Monitoring for Heavy Metal Pollutants, Hunan Ecological Environment Monitoring Center, Changsha 410082, People's Republic of China 
emission spectroscopy (ICP-AES) [3], inductively coupled plasma mass spectrometry (ICP-MS) [4], and atomic absorption spectroscopy (AAS) [5]. However, these methods still suffer from possible contamination of samples during transportation, complicated pre-treatment processes, and high detection cost. Alternatively, the electrochemical detection approach based on square wave anodic stripping voltammetry (SWASV) is attractive because of its simplicity, high sensitivity, good rapidity, and possible implementation for online monitoring, thereby worth developing for HMIs determination [6]. Although SWASV has these advantages, the usual problems are poor stability and limited detection elements when detecting heavy metals at lower concentrations. Therefore, in order to improve the stability of the electrode, this article introduces the number of active sites to greatly increase the content of adsorbed heavy metal elements to improve the stability; it increases the number of detected elements by increasing the types of active sites. So, improving electrode surface performance is essential. Such features would include the existence of more adsorption sites and large specific surface area, more conducive to the enrichment and loading of heavy metals.

So far, various materials with high specific surface area and specific electrical conductivity have been designed and synthesized for the detection of heavy metal ions. These include carbon nanotubes [7], graphite [8], graphene [9], and quantum dots [10]. Such materials are characterized by good conducting properties and high surface-to-volume ratio, useful for improving the analytical performance of sensors. However, such materials are still limited in terms of pore size and low efficiency as post modification can hardly expose more active sites for efficient sensing. Currently, porous materials have been used for the preparation of electrode materials due to their regular pore size, larger specific surface area, and the presence of more active sites [11]. Covalent organic frameworks (COFs) are porous materials that attracted increasing attention because of their regular pore structure, high surface area, and tunable chemistry [12]. For instance, COF materials have been explored in various fields, such as energy storage [13], optoelectronics [14], catalysis [15], sensors [16], and many other domains [17]. However, the fewer active sites of COFs induced by their rich pore structures have limited their applications in sensors. This can be solved by postsynthetic modification to provide more active sites [18]. To increase the number of active sites, thiol and amino groups can be employed as functional groups. The resulting modified materials on the sensor surface can capture more heavy metal ions due to the increased number of active sites. Therefore, the high concentration of heavy metal ions on the sensor surface can be stripped into electrochemical signals for quantitative analysis.

Currently, numerous materials containing thiol and amino groups are being used as modification candidates. These include succinic anhydride [19], 1, 2-ethanedithiol [20], ethanethiol [21], and trithiocyanuric acid [22]. Among these, trithiocyanuric acid (1, 3, 5-triazinan-2, 4, 6-trithiol, or TTC) is a highly effective metal scavenger for many electron donor atoms, such as sulfur and nitrogen. Compared with other heavy metal scavengers, on the one hand, TTC has a weak odor and low toxicity [23], which is more environmentally friendly. On the other hand, the reagent contains a large number of sulfhydryl and amino functional groups, so it has the potential to increase the number of active sites. In sum, the combination of the large specific surface area of COF materials with the high active site of trithiocyanuric acid may improve the capture ability of heavy metal ions on the electrode surface. Meanwhile, COF-based materials have been utilized as electrode modification material to improve the sensitivity and detection limit. On the other hand, though this solves issues related to the number of active sites, most COFs still suffer from poor conductivity during the electrochemical sensing. The coupling of COFs with conducting materials, such as graphene, multi-walled carbon nanotubes, and iodine, may solve this limitation. Among these, graphene is a good electrode material widely used for the preparation of sensors.

In this work, a new type of electrochemical sensors based on intercalated COF-SH/graphene structure nanocomposite was developed for the high sensitivity and selectivity determination of trace $\mathrm{Cd}$ (II), $\mathrm{Pb}$ (II), $\mathrm{Cu}$ (II), and $\mathrm{Hg}$ (II). The combination of COF-SH and graphene provided large specific surface areas, abundant active sites of COF-SH, and excellent conductivity due to the presence of graphene. As a result, the constructed sensor showed excellent anti-interference ability, good stability, and low detection limit toward the sensing of heavy metal ions. The applications of the modified electrode for actual sample detection were also studied.

\section{Experimental}

\section{Materials and reagents}

1, 3, 5-Tris (4-aminophenyl) benzene (Tab) and 2, 5divinylterephthalaldehyde (Dva) were obtained from Jilin Science Research Technology Co., Ltd. (Jilin, China). 1, 2Dichlorobenzene, n-butanol, glacial acetic acid, 1, 4-dioxane, trithiocyanuric acid, tetrahydrofuran 2, 2'-azobis (2methylpropionitrile), and other chemicals were all purchased from Aladdin Reagent Co., Ltd. (Shanghai, China). Graphene was provided by Xianfeng Co., Ltd. The stock standard solution of heavy metals was purchased from the National Research Center for Certified Reference Materials (Beijing, China), and working standards were prepared after stepwise dilutions. All chemicals were of analytical grade and used as received. Deionized water $(18.25 \mathrm{M} \Omega \cdot \mathrm{cm})$ was utilized throughout the experiments. 
Fig. 1 (a) FT-IR spectra of TAB, DVA, COF-V, and COF-SH; (b) XRD diffraction patterns of COF$\mathrm{V}$ and theoretical calculation

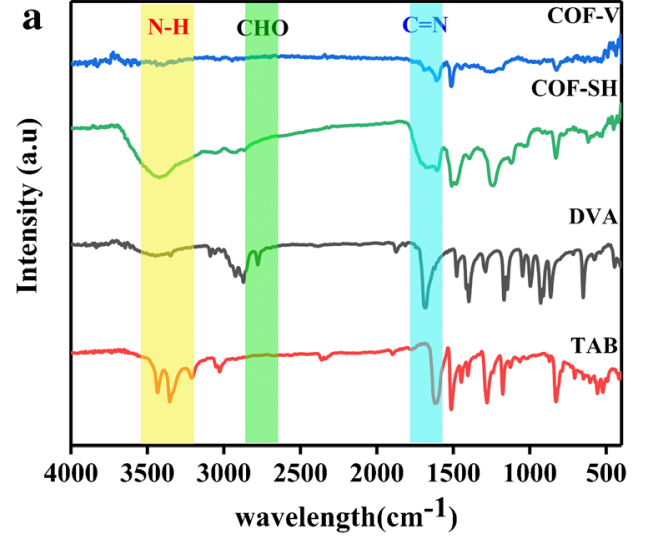

\section{Instruments}

The electrochemical experiments were carried out on a CHI660E electrochemical station (CHI instruments, Shanghai, China). Silver/silver chloride $(\mathrm{Ag} / \mathrm{AgCl}$, Chenhua Instruments, Shanghai, China) was used as a reference, platinum disk $(10 \mathrm{~mm} \times 15 \mathrm{~mm} \times 0.2 \mathrm{~mm}$, Chenhua Instruments, Shanghai, China) as auxiliary, and glassy carbon electrode (GCE, $3 \mathrm{~mm}$ in diameter, Chenhua Instruments, Shanghai, China) as working electrode.

Fourier transform infrared spectrometry (FT-IR) measurements were recorded on a Nicolet iS50 (USA) using the $\mathrm{KBr}$ pellet technique. The morphology and element composition of the nanocomposites were examined by scanning electron microscopy (SEM, Hitachi S-4800, Japan). The crystallinity was analyzed using X-ray diffraction (XRD, Brucker D8 Advance, Germany) with $\mathrm{Cu}$ Ka radiation source operating at $40 \mathrm{kV}$ voltage and $40 \mathrm{~mA}$ current in the $2 \theta$ range of $2-40^{\circ}$. The Brunauer-Emmett-Teller (BET) surface areas of the samples were measured by recording the $\mathrm{N}_{2}$ adsorption-desorption spectra (ASAP2460, USA).

\section{Preparation of COF-SH}

First, prepare and synthesize COF-V. This material has been reported in the previous literature [24] (The specific synthesis method can be seen in the Supporting Information). COF-V $(100 \mathrm{mg})$ was sonicated in a $50-\mathrm{mL}$ round bottom flask containing $5 \mathrm{~mL} \mathrm{1,} \mathrm{4-dioxane} \mathrm{under} \mathrm{N}_{2}$ atmosphere. Afterward, AIBN (10 mg) and trithiocyanuric acid (100 mg) were added to the mixture under stirring in $\mathrm{N}_{2}$ atmosphere, followed by stirring at $80{ }^{\circ} \mathrm{C}$ for $48 \mathrm{~h}$. The resulting product was isolated and washed several times with methanol and acetone to yield a yellow powder after drying under vacuum at $70{ }^{\circ} \mathrm{C}$ for $24 \mathrm{~h}$.

\section{Preparation of modified electrodes}

The GCE was first polished to a mirror-like surface using $0.3 \mu \mathrm{m}$ and $0.05 \mu \mathrm{m} \gamma$-alumina slurries, and then washed with water and ethanol for $1 \mathrm{~min}$ in an ultrasonic bath before drying in air. High levels of graphene led to fewer adsorption sites and elevated contents of COF material induced lower conductivities. Under the optimized conditions, $2 \mathrm{mg}$ COF-SH and $2 \mathrm{mg}$ graphene were placed in a sample tube followed by the addition of $1 \mathrm{~mL}$ water and $0.05 \mathrm{~mL}$ Nafion to yield a uniform solution after sonication. An aliquot of G/COF-SH $(10 \mu \mathrm{L})$ solution was then dripped onto the clean GCE surface to form G/COF-SH/GCE. For comparison, the COF-SH/GCE was also prepared in the same procedure without graphene; the G GCE was also prepared in the same procedure without $\mathrm{COF}-\mathrm{SH}$; and $\mathrm{G} / \mathrm{COF}-\mathrm{V}$ was also prepared in the same procedure with COF-V instead of COF-SH.
Fig. 2 (a) $\mathrm{CV}$ and (b) EIS of the bare GCE and COF-SH, G/COF$\mathrm{V}$ and $\mathrm{G} / \mathrm{COF}-\mathrm{SH}$ electrodes $(\mathrm{CV}$ and EIS measurements were performed using a solution of $5.0 \mathrm{mM}\left[\mathrm{Fe}(\mathrm{CN})_{6}\right]^{3-/ 4-}$ solutions $)$.
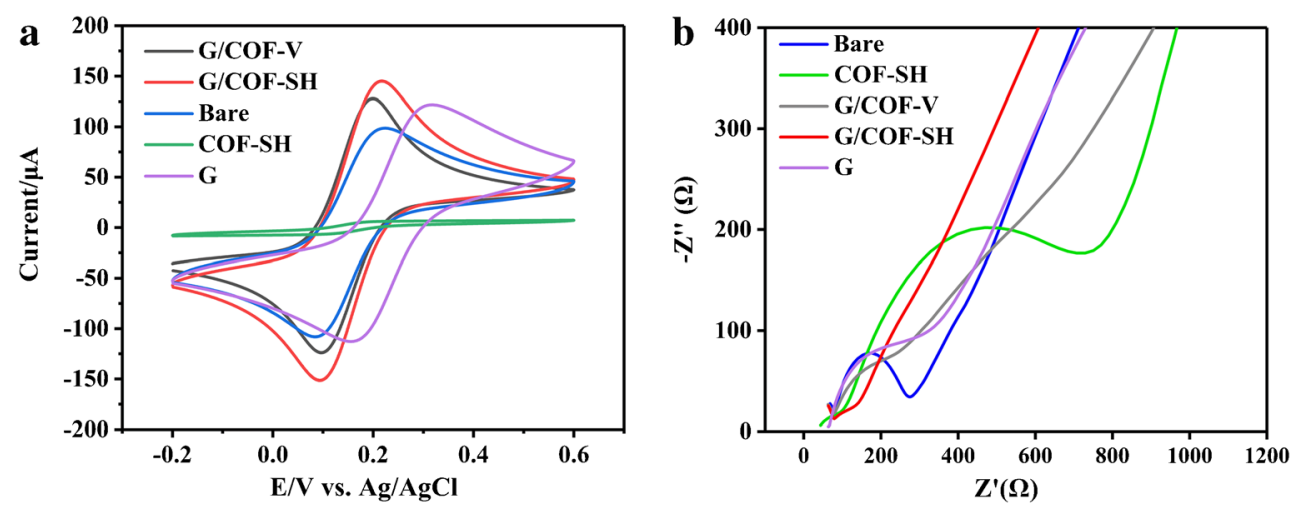

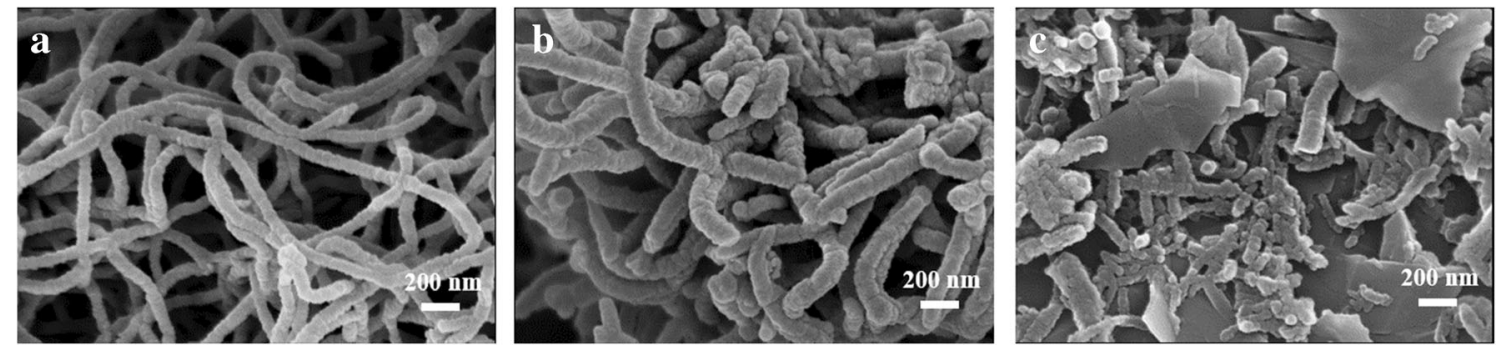

Fig. 3 SEM images of COF-V (a), COF-SH (b), and G/COF-SH (c), respectively

\section{Determination of HMls}

The detection experiments were performed on a CHI660E electrochemical workstation with the Square Wave Voltammetry (SWV) technique. To this end, the working electrode modified with the synthesized materials was first immersed in acetate buffer $(0.1 \mathrm{M})$ containing different concentrations of $\mathrm{Cd}$ (II), $\mathrm{Pb}$ (II), $\mathrm{Cu}$ (II), and $\mathrm{Hg}$ (II) ions. The $\mathrm{pH}$ of the acetate buffer solution was fixed to 5.0. Four heavy metal ions were subject to deposition at $-1.2 \mathrm{~V}$ for $400 \mathrm{~s}$ under constant stirring. After deposition, the stirring process was stopped and the electrode was left to stand for $10 \mathrm{~s}$. Next, the response curves were recorded from -1.0 to $0.4 \mathrm{~V}$. Before the next measurement, the modified electrode was cleaned by applying a potential of $0.4 \mathrm{~V}$ for $60 \mathrm{~s}$. The sensitivity of the detection was estimated by analyzing the relationship between the current and concentration.

\section{Results and discussion}

\section{Materials characterization}

Here, hydrosulphonyl functional COF (COF-SH) materials were synthesized by a two-step route. First, normal COFs $(\mathrm{COF}-\mathrm{V})$ were synthesized by the solvothermal method and then followed by modification with trithiocyanuric acid to form COF-SH. The structures of COF-V and COF-SH products were characterized by various techniques, such as FT-IR, XRD, TGA, and EDS. Compared to monomers (DVA and TAB), the FT-IR spectra of COF-V showed a new characteristic peak at $1610 \mathrm{~cm}^{-1}(\mathrm{C}=\mathrm{N})$. However, the peaks of $\mathrm{N}-\mathrm{H}$ $\left(3436 \mathrm{~cm}^{-1}\right.$ and $\left.3352 \mathrm{~cm}^{-1}\right)$ associated with the stretching vibrations of Tab, as well as the $\mathrm{C}=\mathrm{O}\left(1683 \mathrm{~cm}^{-1}\right)$ stretching vibration peak of Dva all vanished. Hence, the amino group and aldehyde group reacted during the synthesis process. Compared to COF-V, the C-S weak characteristic band was visible in the FT-IR spectrum of COF-SH at $670 \mathrm{~cm}^{-1}$, confirming the modification of trithiocyanuric acid on COFV surface (Fig. 1(a)).

To further characterize the crystallinity of the as-obtained materials, XRD was used and the results are gathered in Fig. 1(b). The XRD patterns of COF-V and COF-SH illustrated a strong peak at $2.77^{\circ}$. Relatively weak peaks at $4.71^{\circ}, 5.49^{\circ}$, $7.3^{\circ}, 9.5^{\circ}$, and $25.35^{\circ}$ were also observed and attributed to (100), (110), (200), (210), (220), and (001) crystal planes, respectively. The Pawley refinements of COF-V were carried out for full profile fitting against the proposed model of AA packing, and the data showed good agreement factors $\left(R_{\mathrm{WP}}=\right.$ $8.01 \%$ and $R_{\mathrm{p}}=4.9 \%$ ). After modification, the special structure of the newly produced material may impact the structure of COF-V, leading to slight distortion in crystallinity that may be due to the influence of flexible chain with internal pores of COF-V (Fig. S1).

The elements of COF-SH are analyzed. The EDS elemental maps show that the modified COF-SH mainly contains $\mathrm{C}, \mathrm{O}$, $\mathrm{N}$, and S (Fig. S2, Supporting Information). In the EDS spectrum of COF-SH and COF-V (Fig. S2, Supporting Information), COF-SH obviously increases the $\mathrm{S}$ element. In addition, we also performed TGA and BET analyses on the materials (Fig. S3 and Fig. S4, Supporting Information). The results show that the BET of the modified COF material is reduced, which is consistent with the XRD test results, but the thermal stability of the material remains unchanged at about $200^{\circ} \mathrm{C}$.

\section{Electrochemical behaviors of COF-SH-based electrodes}

Based on the heavy metal adsorption properties of COF-SH, COF-based electrodes were constructed and tested toward the detection of heavy metals by CV and EIS techniques. As shown in Fig. 2a, the CV plot of the control electrode (bare GCE) showed a pair of redox peaks with intensities of 98.69 and $-108.17 \mu \mathrm{A}$. By comparison, COF-SH-modified electrode displayed declined oxidation and reduction current intensities of 5.47 and $-6.05 \mu \mathrm{A}$, respectively. Thus, despite the many active functional groups of COF-SH, its electrochemical response was still weak. By contrast, the addition of graphene

Fig. 4 SWV responses of the G/COF-SH electrode to $\mathrm{Cd}$ (II), $\mathrm{Pb}$ (II), $\mathrm{Cu}$ (II), and $\mathrm{Hg}$ (II). (a, b, c, and d). The calibration plots of the peak current to corresponding concentrations (1(5), 10,30,50,100,200,400,600, $800,1000 \mu \mathrm{g} \mathrm{L}^{-1}$ ) of $\mathrm{Cu}$ (II), $\mathrm{Pb}$ (II), Cd (II), and $\mathrm{Hg}$ (II) (e, f, g, and h) respectively 

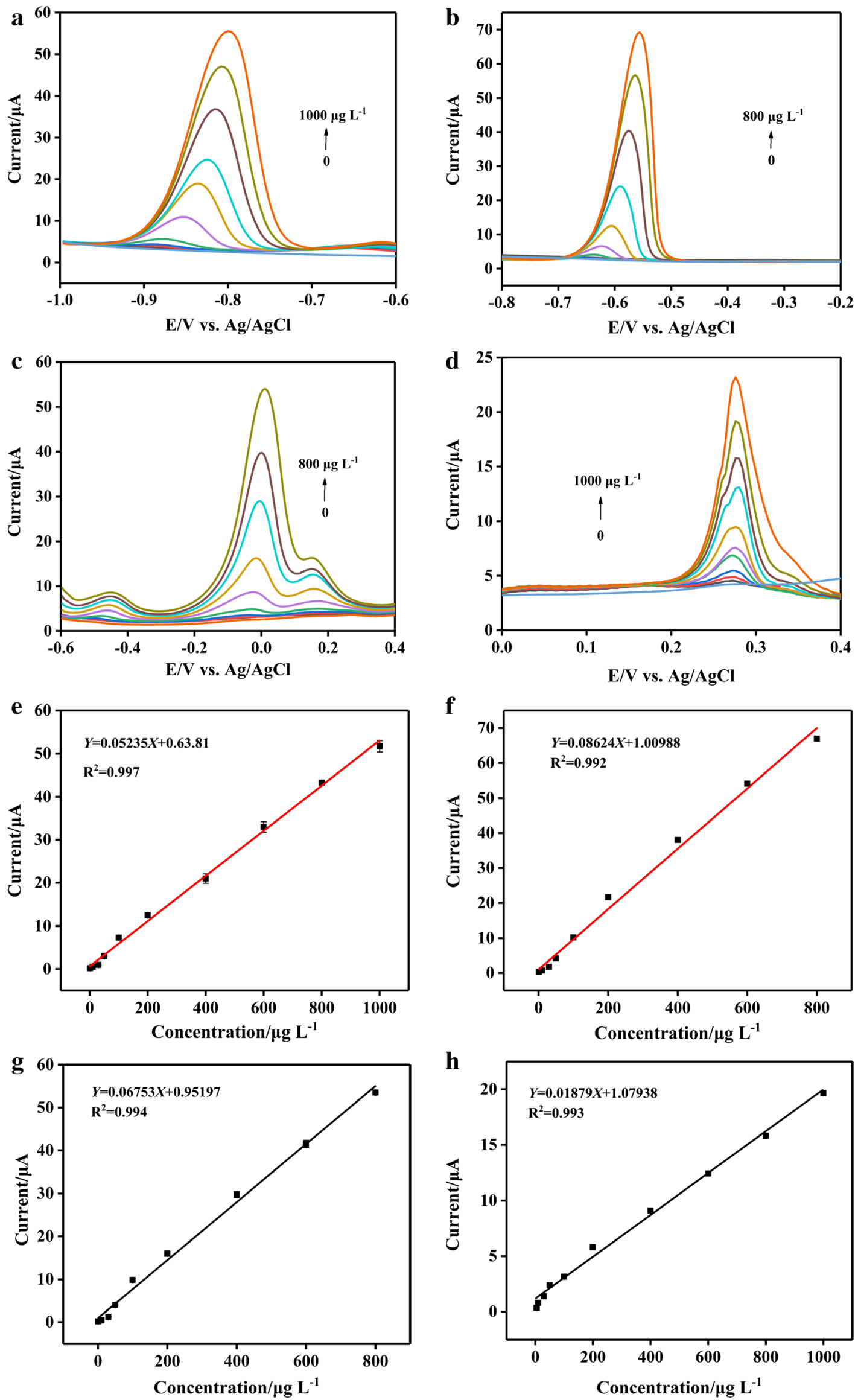
enhanced the oxidation peaks (black line, G/COF-V, and red line, G/COF-SH) in Fig. 2a, with intensities reaching 128 and $-123 \mu \mathrm{A}$ for $\mathrm{G} / \mathrm{COF}-\mathrm{V}$, and 145.33 and $-151.10 \mu \mathrm{A}$ for $\mathrm{G} / \mathrm{COF}-\mathrm{SH}$, respectively.

The electron transfer rates of these electrodes were explored by EIS using $[\mathrm{Fe}(\mathrm{CN}) 6]^{3-} / /^{4-}$ as an electrochemical probe. Compared to bare GCE (Fig. 2b), G/COF-V and G/ $\mathrm{COF}-\mathrm{SH}$ electrodes exhibited inconspicuous electron transfer resistances with smaller radii, while $\mathrm{COF}-\mathrm{SH}$ electrode illustrated a conspicuous electron transfer resistance with a bigger radius. Besides, $\mathrm{G} / \mathrm{COF}-\mathrm{SH}$ revealed a lower capacitance than $\mathrm{G} / \mathrm{COF}-\mathrm{V}$, resulting in a faster electron transfer.

The morphologies of these electrodes were further viewed by SEM. As shown in Fig. 3, COF-V (Fig. 3a) displayed a fiber-like structure with an average diameter of about $100 \mathrm{~nm}$. By comparison, COF-SH (Fig. 3b) retained its fiber-like structure but showed a bigger particle diameter. The mixing of COF-SH with graphene under ultrasonic treatment fragmented COF-SH into pieces, leading to their intercalation with graphene (Fig. 3c). This process improved the electrochemical responses.

Moreover, G/COF-SH provided greater electrical activity areas and more active sites, thereby promoting better electron transfer between the electrode substrate and deposited materials.

\section{Electrochemical sensing of heavy metal ions}

The electrochemical performances of $\mathrm{G}, \mathrm{COF}-\mathrm{V}, \mathrm{G} / \mathrm{COF}-\mathrm{V}$, and $\mathrm{G} / \mathrm{COF}-\mathrm{SH}$ electrodes toward the determination of $\mathrm{Cd}$ (II), $\mathrm{Pb}$ (II), $\mathrm{Cu}$ (II), and $\mathrm{Hg}$ (II) metal ions were evaluated in acetic acid/sodium acetate buffer solution $(0.1 \mathrm{M}, \mathrm{pH}=5.0)$ at certain concentrations of the metal ions. After deposition time of $400 \mathrm{~s}$ at potential of $-1.2 \mathrm{~V}, \mathrm{G} / \mathrm{COF}-\mathrm{SH}$ electrode showed a higher current and well-defined peak than other electrodes (Fig. S5). The current peaks of $\mathrm{Cu}, \mathrm{Pb}, \mathrm{Cd}$, and $\mathrm{Hg}$ detected by G/COF-SH electrode were 1.2-, 6.0-, 1.3-, and 1.1-fold larger than those of $\mathrm{G} / \mathrm{COF}-\mathrm{V}$ electrode. The presence of graphene functioned as an excellent electron transporter, substantially improving the response signals. After modification with thiol-materials, the increase in active sites of COF-SH adsorbed more heavy metal elements. As a result, G/COF-SH electrode shows more obvious advantages on detection of heavy metal ions.

\section{Optimized detection conditions}

The electrochemical redox behavior of HMIs by G/COF-SH electrodes was investigated in acetate buffer at $\mathrm{pH}$ values varying from 3.5 to 7.0. To this end, SWV was employed and the changing trend is shown in Fig. S6(a). Obviously, G/COF-SH electrodes were affected by $\mathrm{pH}$, and SWV current increased with $\mathrm{pH}$ value from 3.5 to 5.0 but decreased at $\mathrm{pH}$ 7.0. As shown in Fig. S6(a), better detection of heavy metal ions was achieved in a slightly acidic environment. Therefore, $\mathrm{pH} 5.0$ was selected as the optimal value for subsequent experiments.

Since the accumulation potential significantly affected the stripping voltammetric response of HMIs, it was evaluated on the peak current signal response of $1 \mathrm{mg} \mathrm{L}^{-1} \mathrm{Cd}$ (II), $\mathrm{Pb}$ (II), $\mathrm{Cu}$ (II), and $\mathrm{Hg}$ (II) by $\mathrm{G} / \mathrm{COF}-\mathrm{SH}$ electrodes at potentials from -0.9 to $-1.3 \mathrm{~V}$. At optimized accumulation potential of $-1.2 \mathrm{~V}$ (Fig. S6(b)), the peak currents of Cd (II), Pb (II), $\mathrm{Cu}$ (II), and $\mathrm{Hg}$ (II) reached extreme values.

Since the deposition time should also affect the peak current of HMIs detection, it was optimized as well. As shown in Fig. S6(c), the peak currents of Cd (II), $\mathrm{Pb}$ (II), $\mathrm{Cu}$ (II), and $\mathrm{Hg}$ (II) reached higher values at $400 \mathrm{~s}$.

In real sample analysis processes, four heavy metals may exist simultaneously, thereby would be important to detect all of them. The SWV responses of four heavy metal ions were studied at increasing concentrations under the optimal
Table 1 Analytical results of various electrochemical sensors

\begin{tabular}{|c|c|c|c|c|}
\hline Electrode material & Detection & Liner range $\left(\mu \mathrm{g} \mathrm{L}^{-1}\right)$ & $\operatorname{LOD}\left(\mu \mathrm{g} \mathrm{L}^{-1}\right)$ & Ref. \\
\hline $\mathrm{N}, \mathrm{S}$-rich $\mathrm{COF}_{\mathrm{BTT}-\mathrm{TZT}}$ & $\mathrm{Hg}$ (II) & $108-1.0 \times 10^{\wedge} 3$ & 36.1 & {$[25]$} \\
\hline $\mathrm{NH}_{2}$-MIL-53(Al)/PPy & $\mathrm{Pb}$ (II) & $1-400$ & 0.3 & {$[26]$} \\
\hline \multirow[t]{4}{*}{$\mathrm{COF}_{\mathrm{BTLP}-1} / 3 \mathrm{D}-\mathrm{KSC}$ electrode } & $\begin{array}{l}\mathrm{Cu} \text { (II) } \\
\mathrm{Cd} \text { (II) }\end{array}$ & $\begin{array}{l}1-400 \\
4.2-2.0 \times 10^{\wedge} 3\end{array}$ & $\begin{array}{l}0.2 \\
1.4\end{array}$ & \multirow[t]{4}{*}[27]{} \\
\hline & $\mathrm{Pb}$ (II) & $7.5-3.7 \times 10^{\wedge} 3$ & 2.4 & \\
\hline & $\mathrm{Cu}$ (II) & $3.6-1.2 \times 10^{\wedge} 3$ & 1.2 & \\
\hline & $\mathrm{Hg}$ (II) & $13-3.6 \times 10^{\wedge} 3$ & 4.3 & \\
\hline TAPB-DMTP-COF & $\mathrm{Pb}$ (II) & $1-414$ & 0.4 & {$[28]$} \\
\hline \multirow[t]{4}{*}{$\mathrm{G} / \mathrm{COF}-\mathrm{SH} / \mathrm{GCE}$} & $\mathrm{Cd}$ (II) & $1-1.0 \times 10^{\wedge} 3$ & 0.3 & \multirow[t]{4}{*}{ This work } \\
\hline & $\mathrm{Pb}$ (II) & $1-800$ & 0.2 & \\
\hline & $\mathrm{Cu}$ (II) & $1-800$ & 0.2 & \\
\hline & $\mathrm{Hg}$ (II) & $5-1.0 \times 10^{\wedge} 3$ & 1.1 & \\
\hline
\end{tabular}


Table 2 Analytical results for the detection of $\mathrm{G} / \mathrm{COF}-\mathrm{SH}$ in coastal water

\begin{tabular}{lllll}
\hline Analytes & Spiked $\left(\mu \mathrm{g} \mathrm{L}^{-1}\right)$ & Found $\left(\mu \mathrm{g} \mathrm{L}^{-1}, n=3\right)$ & Recovery $(\%)$ & ICP-Ms $\left(\mu \mathrm{g} \mathrm{L}^{-1}\right)$ \\
\hline $\mathrm{Cd}$ & 0 & $\mathrm{ND}$ & & $\mathrm{ND}$ \\
& 10 & $10.1 \pm 0.6$ & 100.6 & \\
& 20 & $20.5 \pm 1.4$ & 102.7 & $9.8 \pm 0.1$ \\
$\mathrm{~Pb}$ & 0 & $10.2 \pm 0.6$ & & \\
& 10 & $21.7 \pm 3.3$ & 115.3 & \\
& 20 & $30.5 \pm 1.7$ & 102.9 & \\
$\mathrm{Cu}$ & 0 & $39.2 \pm 0.3$ & & \\
& 10 & $49.6 \pm 0.4$ & 101.0 & $\mathrm{ND}$ \\
& 20 & $63.3 \pm 3.3$ & 110.5 & \\
$\mathrm{Hg}$ & 0 & $\mathrm{ND}$ & 103.5 & \\
& 10 & $10.4 \pm 0.1$ & 103.1 & \\
\end{tabular}

conditions. As shown in Fig. S6(d), the G/COF-SH sensor simultaneously detected the four heavy metal ions. The oxidation potentials of $\mathrm{Cd}$ (II), $\mathrm{Pb}$ (II), $\mathrm{Cu}$ (II), and $\mathrm{Hg}$ (II) were approximately located at $-0.9 \mathrm{~V},-0.65 \mathrm{~V},-0.1 \mathrm{~V}$, and $0.2 \mathrm{~V}$, respectively. The currents of $\mathrm{Cd}$ (II) and $\mathrm{Pb}$ (II) looked higher due to the enhanced sensitivity of G/COF-SH-modified GCE to $\mathrm{Cd}$ (II) and $\mathrm{Pb}$ (II).

\section{Individual detection of $\mathrm{Cd}$ (II), $\mathrm{Pb}$ (II), $\mathrm{Cu}$ (II), and $\mathrm{Hg}$ (II)}

Further experiments were performed under the optimal conditions for single ion determination. As displayed in Fig. 4, the SWV responses of four heavy metal ions linearly increased with concentration. The stripping peaks at $-0.8,-0.55,0.00$, and $0.25 \mathrm{~V}$ were attributed to the existence of $\mathrm{Cd}$ (II), $\mathrm{Pb}$ (II), $\mathrm{Cu}$ (II), and $\mathrm{Hg}$ (II), respectively. The corresponding correlation coefficients of G/COF-SH toward the detection of these metal ions were recorded as 0.997, 0.992, 0.994, and 0.993, respectively. The detection limits of $\mathrm{Cd}$ (II), $\mathrm{Pb}$ (II), $\mathrm{Cu}$ (II), and $\mathrm{Hg}$ (II) were estimated to be $0.3,0.2,0.2$, and $1.1 \mu \mathrm{g} \mathrm{L}{ }^{-1}$, respectively. The corresponding linear ranges were 1$1000 \mu \mathrm{g} \mathrm{L}^{-1}, 1-800 \mu \mathrm{g} \mathrm{L}^{-1}, 1-800 \mu \mathrm{g} \mathrm{L}^{-1}$, and 5$1000 \mu \mathrm{g} \mathrm{L}^{-1}$, respectively. The linear regression equations of $\mathrm{Cd}$ (II), $\mathrm{Pb}$ (II), $\mathrm{Cu}$ (II), and $\mathrm{Hg}$ (II) were recorded as $Y=$ $0.052 X-0.64\left(R^{2}=0.997\right), Y=0.086 X-1.01\left(R^{2}=0.992\right), Y=$ $0.068 X-0.95\left(R^{2}=0.994\right)$, and $Y=0.019 X-1.079\left(R^{2}=0.993\right)$, respectively. Here, $X$ is the concentration of heavy metal ions, and $Y$ is the corresponding peak current. LOD is based on the $3 \sigma / S$ criterion (where $\sigma$ is the standard deviation and $S$ is the slope of the calibration plot).

To further confirm the advantages of G/COF-SH electrodes for HMI determination, the proposed sensor was compared to reported sensing devices. As depicted in Table 1, compared with the newly reported sensor related to COFs, G/COF-SH/ GCE has a better detection limit, can be used for the determination of a variety of heavy metal elements, and has a better linear range. The superiority of G/COF-SH/GCE is mainly manifested in two ways: (1) The COFs material has a larger specific surface area, and provides more active sites to chelate metal cations after being modified by sulfhydryl groups, which improves the electrochemical response. (2) Graphene enhances the conductivity of the overall material and further improves the electrochemical signal. Therefore, post-modified COFs combined with nanomaterials with strong conductivity are ideal materials for the development of electrochemical sensors in the future.

\section{Repeatability of G/COF-SH sensor}

The stability of G/COF-SH electrodes was studied by detecting $\mathrm{Cd}$ (II), $\mathrm{Pb}$ (II), $\mathrm{Cu}$ (II), and $\mathrm{Hg}$ (II) for six times. As shown in Fig. S7, the current values remained almost the same with relative deviations of peak current within $5 \%$.

The anti-interference ability of the obtained sensor was also explored in the presence of potentially interfering species, such as $\mathrm{K}$ (I), $\mathrm{Na}$ (I), Ca (II), Mg (II), Fe (III), Zn (II), Ni (II), Mn (II), Cr (II), Ag (I), Co (II), Bi (III), and Se (IV) at concentrations five-fold higher than those of $\mathrm{Cd}$ (II), $\mathrm{Pb}$ (II), $\mathrm{Cu}$ (II), and $\mathrm{Hg}$ (II). The addition of five-fold interferences to a mixed solution containing the four heavy metals illustrated no effect on the current response. Hence, the obtained sensor was highly selective toward the detection of $\mathrm{Cd}$ (II), $\mathrm{Pb}$ (II), $\mathrm{Cu}$ (II), and $\mathrm{Hg}$ (II) metal ions.

\section{Analysis of real samples}

To verify the practicality of the proposed electrochemical sensors, G/COF-SH electrodes were tested in coastal water (The sample pretrement method is in the Supporting Information). The SWV results revealed the presence of some HMIs, indicating samples containing only some analytes with other 
target analytes at very low concentrations. To ensure accuracy, the electrochemical determination results were compared to those obtained by ICP-MS. As shown in Table 2, the proposed electrochemical method could simultaneously detect HMIs in real samples with high accuracy and feasibility.

\section{Conclusions}

Hydrosulphonyl functional COF (COF-SH) materials were successfully synthesized. The morphological and structural characterizations of the synthesized hydrosulphonyl functional COFs were carried out by SEM, EDS, XRD, TGA, and FT-IR techniques. The abundance of active sites of SH on COF-SH enhanced the adsorption ability of heavy metals. After combination with graphene, the nanocomposite was used as an electrode material for the determination of heavy metals. Due to the synergism between graphene and trithiocyanuric acid, trithiocyanuric acid exhibits both the large HMI adsorption capacity of COF-SH and good conductivity of the graphene, which significantly increases the electrochemical response of G/COF-SH electrode toward heavy metal ions. The detection limits were lower than the guideline values provided by WHO. The G/COF-SH-modified electrode also performed well in terms of stability and anti-interference ability, as well as the determination of metal ions in real coastal water samples. However, when encountering samples with a relatively complex matrix with low heavy metal content, the stability of the electrode needs to be further improved. In sum, the assembled sensor looks potential for the detection of HMIs in real samples.

Supplementary Information The online version contains supplementary material available at https://doi.org/10.1007/s00604-021-04956-1.

Funding This work was supported by the Basic Research Fund for Central Universities (531118010314), the Environmental Protection Science and Technology Project of Hunan Province (20190011), the National Key R\&D Program of China (2019YFD0901103), the Strategic Priority Research Program of Chinese Academy of Sciences (XDB42000000), and the Key R \& D Program of Hunan Province (2019SK2281).

\section{Declarations}

Conflict of interest The authors declare no competing interests.

\section{References}

1. Awual R, Hasan M, Islam A, Rahman MM, Asiri AM, Khaleque A, Sheikh C (2019) Offering an innovative composited material for effective lead (II) monitoring and removal from polluted water. J Clean Prod 231:214-223. https://doi.org/10.1016/j.jclepro.2019. 05.125
2. Gaulier C, Zhou C, Guo W, Bratkic A, Superville P, Billon G, Baeyens W, Gao Y (2019) Trace metal speciation in North Sea coastal waters. Sci Total Environ 692:701-712. https://doi.org/10. 1016/j.scitotenv.2019.07.314

3. Sun Z, Liu Y, Srinivasakannan C (2020) One-pot fabrication of rod-like magnesium silicate and its adsorption for $\mathrm{Cd}^{2+}$. J Environ Chem Eng 8:104380. https://doi.org/10.1016/j.jece.2020.104380

4. Horak F, Nagl A, Föttinger K, Limbeck A (2020) Application of micro-dried droplets for quantitative analysis of particulate inorganic samples with LA-ICP-MS demonstrated on surface-modified nanoparticle $\mathrm{TiO}_{2}$ catalyst materials. Microchim Acta 187:641. https://doi.org/10.1007/s00604-020-04609-9

5. Huang Y, Zhang S, Chen Y, Wang L, Long Z, Hughes SS, Ni S, Cheng X, Wang J, Li T, Wang R, Liu C (2020) Tracing Pb and possible correlated $\mathrm{Cd}$ contamination in soils by using lead isotopic compositions. J Hazard Mater 385:121528. https://doi.org/10.1016/ j.jhazmat.2019.121528

6. Pan DW, Wang Y, Chen Z, Lou T, Qin W (2009) Nanomaterial/ ionophore-based electrode for anodic stripping voltammetric determination of lead: an electrochemical sensing platform toward heavy metals. Anal Chem 81:5088-5094. https://doi.org/10.1021/ ac900417e

7. Schroeder V, Savagatrup S, He M, Lin S, Swager TM (2019) Carbon nanotube chemical sensors. Chem Rev 119:599-663. https://doi.org/10.1021/acs.chemrev.8b00340

8. Tesarova E, Baldrianova L, Hocevar SB, Svancara I, Vytras K, Ogorevc B (2009) Anodic stripping voltammetric measurement of trace heavy metals at antimony film carbon paste electrode. Electrochim Acta 54:1506-1510. https://doi.org/10.1016/j. electacta.2008.09.030

9. Nehru R, Hsu YF, Wang SF, Dong CD, Govindasamy M, Habila MA, AlMasoud N (2021) Graphene oxide@Ce-doped $\mathrm{TiO}_{2}$ nanoparticles as electrocatalyst materials for voltammetric detection of hazardous methyl parathion. Microchim Acta 188:216. https://doi. org/10.1007/s00604-021-04847-5

10. Jiao Z, Zhang P, Chen H, Li C, Chen L, Fan H (2019) Differentiation of heavy metal ions by fluorescent quantum dot sensor array in complicated samples. Sensors Actuators B Chem 295:110-116. https://doi.org/10.1016/j.snb.2019.05.059

11. Canossa S, Wuttke S (2020) Functionalization chemistry of porous materials. Adv Funct Mater 30:2003875. https://doi.org/10.1002/ adfm. 202003875

12. Li G, Ye J, Fang QR, Liu F (2019) Amide-based covalent organic frameworks materials for efficient and recyclable removal of heavy metal lead (II). Chem Eng J 370:822-830. https://doi.org/10.1016/j. cej.2019.03.260

13. Shi R, Liu L, Lu Y, Wang C, Li Y, Li L, Yan Z, Chen J (2020) Nitrogen-rich covalent organic frameworks with multiple carbonyls for high-performance sodium batteries. Nat Commun 11:1-10. https://doi.org/10.1038/s41467-019-13739-5

14. Calik M, Auras F, Salonen LM, Bader K, Grill I, Handloser M, Medina DD, Dogru M, Löbermann F, Trauner D, Hartschuh A, Bein T (2014) Extraction of photogenerated electrons and holes from a covalent organic framework integrated heterojunction. $\mathrm{J}$ Am Chem Soc 136:17802-17807. https://doi.org/10.1021/ ja509551m

15. Han X, Xia Q, Huang J, Liu Y, Tan C, Cui Y (2017) Chiral covalent organic frameworks with high chemical stability for heterogeneous asymmetric catalysis. J Am Chem Soc 139:8693-8697. https://doi. org/10.1021/jacs.7b04008

16. Li Y, Chen M, Han Y, Feng Y, Zhang Z, Zhang B (2020) Fabrication of a new corrole-based covalent organic framework as a highly efficient and selective chemosensor for heavy metal ions. Chem Mater 32:2532-2540. https://doi.org/10.1021/acs. chemmater.9b05234 
17. Shinde DB, Cao L, Wonanke ADD, Li X, Kumar S, Liu X, Hedhili MN, Emwas AH, Addicoat M, Huang KW, Lai Z (2020) Pore engineering of ultrathin covalent organic framework membranes for organic solvent nanofiltration and molecular sieving. Chem Sci 11:5434-5440. https://doi.org/10.1039/d0sc01679a

18. Segura JL, Royuela S, Ramos MM (2019) Post-synthetic modification of covalent organic frameworks. Chem Soc Rev 48:39033945. https://doi.org/10.1039/C8CS00978C

19. Shang W, Sheng Z, Shen Y, Ai B, Zheng L (2016) Study on oil absorbency of succinic anhydride modified banana cellulose in ionic liquid. Carbohydr Polym 141:135-142. https://doi.org/10.1016/j. carbpol.2016.01.009

20. Kim T, Lee TK, Kim BS, Park SC, Lee S, Im SS, Bisquert J, Kang YS (2017) Triumphing over charge transfer limitations of PEDOT nanofiber reduction catalyst by 1,2-ethanedithiol doping for quantum dot solar cells. ACS Appl Mater Interfaces 9:1877-1884. https://doi.org/10.1021/acsami.6b12536

21. Ma X, Wu Z, Zhou M, Ding J (2013) Electrochemical scission of C $-\mathrm{S}$ bond in ethanethiol on a modified $\mathrm{b}-\mathrm{PbO}_{2}$ anode in aqueous solution. Sep Purif Technol 109:72-76. https://doi.org/10.1016/j. seppur.2013.02.030

22. Heidari M, Ghanemi K, Nikpour Y (2020) Applying $\mathrm{Al}_{2} \mathrm{O}_{3} @ \mathrm{Ag} @$ trithiocyanuric acid as an efficient metal ion scavenger for the selective extraction of iron (III) and lead (II) from environmental waters. Ecotoxicol Environ Saf 203:110995. https://doi.org/10.1016/j.ecoenv.2020.110995

23. Osaka N, Ishitsuka M, Hiaki T (2009) Infrared reflection absorption spectroscopic study of adsorption structure of self-assembled monolayer film of trithiocyanuric acid on evaporated silver film. J
Mol Struct 921:144-149. https://doi.org/10.1016/j.molstruc.2008. 12.051

24. Deng Y, Zhang Z, Du PY, Ning XM, Wang Y, Zhang DX, Liu J, Zhang ST, Lu XQ (2020) Bridging ultrasmall Au clusters into the pores of a covalent organic framework for enhanced photostability and photocatalytic performance. Angew Chem Int Ed 59:60826089

25. Wang LY, Yang YX, Liang HH, Wu N, Peng X, Wang L, Song YH (2021) A novel N, S-rich COF and its derived hollow N, S-doped carbon@Pd nanorods for electrochemical detection of $\mathrm{Hg}^{2+}$ and paracetamol. J Hazard Mater 409:124528. https://doi.org/10.1016/ j.jhazmat.2020.124528

26. Wang N, Zhao W, Shen ZY, Sun SJ, Dai HX, Ma HY, Lin M (2020) Sensitive and selective detection of $\mathrm{Pb}$ (II) and $\mathrm{Cu}$ (II) using a metal-organic framework/polypyrrole nanocomposite functionalized electrode. Sensor Actuat B-chem 304:127286. https://doi.org/ 10.1016/j.snb.2019.127286

27. Han J, Yu J, Guo Y, Wang L, Song Y (2020) COF BTLP-1 $_{1} /$ threedimensional macroporous carbon electrode for simultaneous electrochemical detection of $\mathrm{Cd}^{2+}, \mathrm{Pb}^{2+}, \mathrm{Cu}^{2+}$ and $\mathrm{Hg}^{2+}$. Sensors Actuators B Chem 321:128498. https://doi.org/10.1016/j.snb. 2020.128498

28. Zhang T, Gao CW, Huang W, Chen YL, Wang Y, Wang JM (2018) Covalent organic framework as a novel electrochemical platform for highly sensitive and stable detection of lead. Talanta 188:578583. https://doi.org/10.1016/j.talanta.2018.06.032

Publisher's note Springer Nature remains neutral with regard to jurisdictional claims in published maps and institutional affiliations. 